\title{
Oral disease and subsequent cardiovascular disease in people with type 2 diabetes: a prospective cohort study based on the Action in Diabetes and Vascular Disease: Preterax and Diamicron Modified-Release Controlled Evaluation (ADVANCE) trial
}

\author{
Q. Li • J. Chalmers · S. Czernichow $\cdot$ B. Neal • \\ B. A. Taylor $\cdot$ S. Zoungas $\cdot$ N. Poulter $\cdot$ M. Woodward • \\ A. Patel • B. de Galan • G. D. Batty • \\ on behalf of the ADVANCE Collaborative group
}

Received: 12 May 2010 / Accepted: 6 July 2010/Published online: 11 August 2010

(C) Springer-Verlag 2010

\begin{abstract}
Aims/hypothesis While there are plausible biological mechanisms linking oral health with cardiovascular disease (CVD) and mortality rates, no study, to our knowledge, has examined this association in a representative population of people with type 2 diabetes.

Methods We used the Action in Diabetes and Vascular Disease: Preterax and Diamicron Modified-Release Controlled Evaluation (ADVANCE) study, a large, detailed, randomised controlled trial among a general population of individuals with type 2 diabetes. For the purposes of the present analyses, data from the trial are used within a
\end{abstract}

Q. Li $\cdot$ J. Chalmers $\cdot \mathrm{S}$. Czernichow $\cdot$ B. Neal $\cdot$ S. Zoungas $\cdot$

M. Woodward · A. Patel - B. de Galan · G. D. Batty

The George Institute for International Health,

Sydney, NSW, Australia

S. Czernichow

Department of Public Health, Avicenne Hospital,

University of Paris 13,

Paris, France

\section{B. A. Taylor}

Department of Oral Biology, University of Oslo,

Oslo, Norway

\section{S. Zoungas}

School of Public Health, Monash University,

Melbourne, VIC, Australia

N. Poulter

Imperial College and St Mary's Hospital,

London, UK prospective cohort study design. A total of 10,958 men and women, aged 55 to 88 years and with type 2 diabetes, participated in a baseline medical examination, during which they counted their number of natural teeth and reported the number of days that their gums had bled over the preceding year. Study members were followed up for mortality and morbidity over 5 years.

Results After controlling for a range of potential confounding factors, the group with no teeth had a markedly increased risk of death due to all causes (HR 1.48, 95\% CI 1.24-1.78), CVD (1.35, 1.05-1.74) and non-CVD (1.64, 1.26-2.13), relative to the group with the most teeth $(\geq 22$ teeth).

M. Woodward

Mount Sinai School of Medicine,

New York, NY, USA

B. de Galan

Radboud University Nijmegen Medical Centre,

Nijmegen, the Netherlands

G. D. Batty

MRC Social \& Public Health Sciences Unit, Glasgow, UK

G. D. Batty $(\bowtie)$

Department of Epidemiology \& Public Health,

University College London,

1-19 Torrington Place,

London WC1E 6BT, UK

e-mail: david.batty@ucl.ac.uk 
Frequency of bleeding gums was not associated with any of the outcomes of interest. There was no suggestion that treatment group or sex modified these relationships.

Conclusions/interpretation In people with type 2 diabetes, oral disease, as indexed by fewer teeth, was related to an increased risk of death from all causes and of death due to CVD and non-CVD.

Keywords Cardiovascular disease $\cdot$ Coronary heart disease $\cdot$ Epidemiology $\cdot$ Oral disease $\cdot$ Stroke

$\begin{array}{ll}\text { Abbreviations } \\ \text { ADVANCE } & \begin{array}{l}\text { Action in Diabetes and Vascular Disease: } \\ \text { Preterax and Diamicron Modified-Release } \\ \end{array} \\ & \begin{array}{l}\text { Controlled Evaluation } \\ \text { Cardiovascular disease }\end{array}\end{array}$

\section{Introduction}

Bacterial infection was first implicated as a cause of cardiovascular disease (CVD) more than a century ago [1]. Although oral disease is the most common type of infectious challenge in humans [2], it is only in the last 20 years that investigators have explored its relationship with CVD and mortality rates in a modest series of studies [3-9]. This association has some plausibility. One possibility is that a local oral bacterial infection may produce systemic effects, leading to an elevation of inflammatory activity, which has itself been implicated in atherothrombogenesis $[10,11]$. An alternative, non-causal explanation is that poor oral health is simply a marker of significant co-morbidity and/or poverty, and that these confounding variables are generating the relationship with CVD.

Oral disease is substantially more common in people with type 2 diabetes than in the general population [12]. Thus, any long-term consequences of oral disease in this group will represent a significant public health burden. Oral disease has been linked with an elevated risk of future CVD in individuals with type 2 diabetes [13]. However, that study sampled only Pima Indians [13], so it is unclear whether the results are applicable to a general population of people with type 2 diabetes.

Accordingly, we used cohort analyses of the Action in Diabetes and Vascular Disease: Preterax and Diamicron Modified-Release Controlled Evaluation (ADVANCE) study [14], a large, detailed, randomised controlled trial among a general population of individuals with type 2 diabetes, to examine the relationship between oral health at study induction and subsequent mortality and morbidity rates.

\section{Methods}

Study background and procedures The ADVANCE trial (ClinicalTrial.gov registration no. NCT00145925), described in detail elsewhere [14], was established to investigate the separate effects of routine blood pressure lowering and intensive glucose control on vascular outcomes in people with type 2 diabetes. In brief, between 2001 and 2003, 11,140 men and women aged 55 to 88 years, and with type 2 diabetes and a history of major macro- or microvascular disease or at least one other cardiovascular risk factor, were recruited from 215 centres (20 countries). Using a factorial design, patients were randomised to perindopril with indapamide or placebo, and to intensive glucose control based on gliclazide modified release or standard glucose control. The flow of participants through the trial is depicted in Fig. 1. For the present analyses, data from the trial were used within a prospective cohort study design, an approach we have taken elsewhere [15]. Approval to conduct the trial was obtained from the Ethics Committee of each study centre; all participants provided written informed consent.

At study induction, participants responded to questionnaires and took part in a medical examination. Individuals with a baseline Mini Mental State Examination [16] score of less than 24 or in whom dementia was suspected were referred to a medically qualified specialist for a possible diagnosis of dementia [17]. Given concerns about the accuracy of self-reported information from people who are cognitively challenged, individuals with such a contemporaneous or prior diagnosis of dementia did not enter the study. $\mathrm{HbA}_{1 \mathrm{c}}$, blood cholesterol (and fractions), blood pressure, resting heart rate and serum creatinine were measured using standard protocols [10]. Height and weight were used to derive BMI $\left(\mathrm{kg} / \mathrm{m}^{2}\right)$. Research staff asked a series of questions regarding ethnicity, educational attainment, physical activity, alcohol intake, cigarette smoking habit, illicit drug use, major chronic disease, assistance with activities of daily living and quality of life (EuroQol fivedimensions questionnaire [EQ-5D]) [18].

Study members also responded to two questions about the presence of oral disease. During the medical examination, they were asked to count the number of natural teeth in their mouth. Artificial teeth were not included, but any tooth or part of a tooth that was visible in the mouth and connected to the gum or jawbone was counted as one tooth. Study members were also asked to report the number of days their teeth had bled in the preceding year. This included spontaneous bleeding, bleeding on cleaning the teeth and bleeding on eating food, but not bleeding associated with dental treatment, tooth loss or facial trauma. Lower numbers of natural teeth and higher numbers of days of gum bleeding indicated poorer oral health. 
Fig. 1 Flow of study participants through the ADVANCE trial

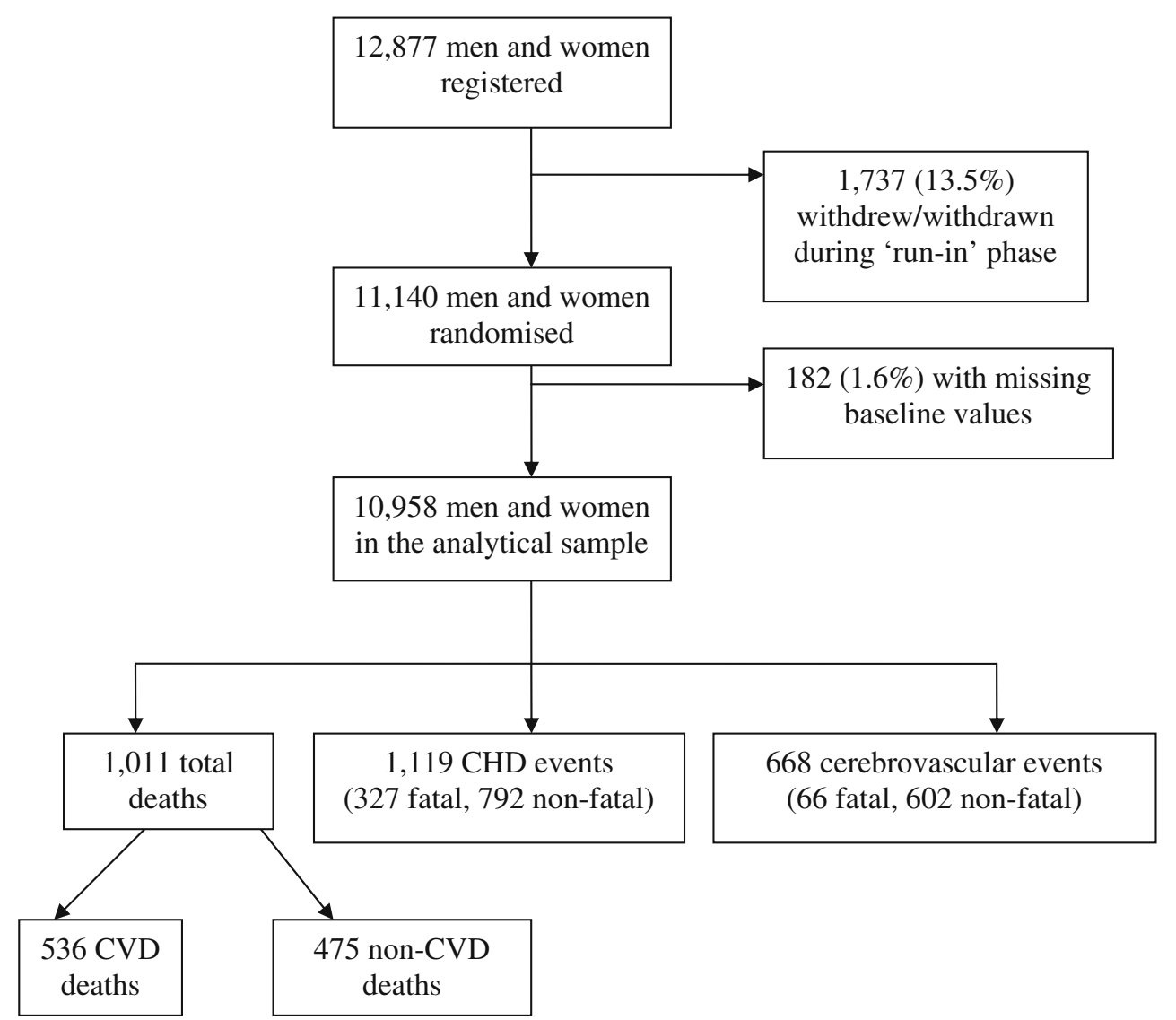

Ascertainment of CVD during follow-up A range of fatal and non-fatal CVD outcomes were ascertained using a variety of sources. Information on cause of death (certification, autopsy report, clinical notes) was scrutinised by an independent Endpoint Adjudication Committee and a coding was assigned according to the 10th revision of the International Classification of Diseases [19]. For non-fatal outcomes, where applicable, clinical notes, computed tomography and magnetic resonance imaging reports (for suspected cerebrovascular disease), laboratory biomarkers (e.g. creatine kinase, troponins) and ECG reports (for suspected myocardial infarction) were used. A CHD event was defined as death due to this condition (including sudden death), non-fatal myocardial infarction, silent myocardial infarction, coronary revascularisation or hospital admission for unstable angina [20]. A cerebrovascular event was defined as death due to this condition or non-fatal stroke, transient ischaemic attack or subarachnoid haemorrhage [20].

Statistical analyses As 182 study members of those randomised had at least one item of missing data, the analytical sample comprised 10,958 participants (Fig. 1). Data for both markers of oral health were skewed. We therefore created three groups each for number of natural teeth $(0,1-21, \geq 22$ teeth) and days of bleeding gums $(0,<12, \geq 12$ days $)$ by taking zero, plus values above zero and separating at the median.
Differences in baseline characteristics across these oral health groups were tested. For categorical variables (e.g. sex) we used the $\chi^{2}$ test; for continuous variables with a normal distribution (e.g. systolic blood pressure) we used an ANOVA; and for continuous variables with a skewed distribution (e.g. exercises and number of alcoholic drinks) we used the Kruskal-Wallis test.

Having first ascertained that the proportional hazards assumption had not been violated, HRs with accompanying 95\% CIs were used to summarise the association between the two markers of oral disease and the various study endpoints [21]. In these analyses, the group with the best oral health ( $\geq 22$ teeth; 0 days with bleeding gums in the last year) represented the reference categories.

The relationship between oral disease and the various health outcomes was first computed separately in the treatment and placebo groups, and in men and women. With no indication that treatment allocation $(p>0.1$ for interaction) or sex ( $p>0.1$ for interaction) modified the association of either marker of oral disease with any of the outcomes, the data were pooled and all analyses were adjusted for treatment, sex and age. The relationship of oral disease with each endpoint was further adjusted for various possible confounding factors, which, after controlling for basic covariates (age, sex and randomised treatment allocation), were organised according to the following 
themes: (1) existing illness (use of metformin/beta-blockers, history of macrovascular or microvascular disease, need for assistance with daily activities, diabetes duration); (2) behavioural CVD risk factors (cigarette smoking, alcohol intake, vigorous physical activity in previous week); (3) physiological CVD risk factors $\left(\mathrm{HbA}_{1 \mathrm{c}}\right.$, creatinine, BMI, total cholesterol, HDL-cholesterol, resting heart rate, systolic BP, diastolic BP); (4) psychological CVD risk factors (quality of life [EQ-5D score], Mini Mental State Examination score); and (5) socioeconomic CVD risk factors (age at completion of highest level of education, height). Multiple adjustment was performed for all these covariates. All analyses were performed using SAS version 9.1 (SAS Institute, Cary, NC, USA).

\section{Results}

In Table 1 we present baseline characteristics according to the two markers of oral disease. At study entry, around one fifth of study members reported complete absence of teeth, while $6.5 \%$ indicated that their gums had bled on 12 days or more in the preceding year. People with fewer natural teeth generally had less favourable biological, social, behavioural and psychological characteristics at study induction. Thus, relative to study members with more teeth, those in the groups with fewer teeth were more likely to be older, less well educated and heavier, and to have elevated systolic BP and serum creatinine, reduced HDL-cholesterol and marginally poorer cognitive function. They were also

Table 1 Oral health and baseline characteristics in ADVANCE ( $n=10,958$ men and women)

\begin{tabular}{|c|c|c|c|c|c|c|c|c|}
\hline \multirow[t]{2}{*}{ Variables } & \multicolumn{3}{|c|}{ Number of natural teeth } & \multirow[t]{2}{*}{$p$ value } & \multicolumn{3}{|c|}{ Days of bleeding gums } & \multirow[t]{2}{*}{$p$ value } \\
\hline & $\geq 22^{\mathrm{a}}$ & $1-21$ & 0 & & $0^{\mathrm{a}}$ & $<12$ & $\geq 12$ & \\
\hline$n$ & 4,476 & 4,174 & 2,308 & & 9,553 & 686 & 719 & \\
\hline $\begin{array}{l}\text { Age at baseline examination } \\
\text { (years) }\end{array}$ & $63.9(5.9)$ & $66.3(6.2)$ & $68.6(6.4)$ & $<0.0001$ & $66.1(6.4)$ & $64.2(6.0)$ & $63.6(5.9)$ & $<0.0001$ \\
\hline $\begin{array}{l}\text { Age at completion of } \\
\text { education (years) }\end{array}$ & $19.3(7.6)$ & $18.3(7.2)$ & $17.0(6.5)$ & $<0.0001$ & $18.3(7.2)$ & $19.4(7.9)$ & $19.4(7.6)$ & $<0.0001$ \\
\hline $\mathrm{HbA}_{1 \mathrm{c}}(\%)$ & $7.5(1.6)$ & $7.5(1.6)$ & $7.5(1.5)$ & 0.1785 & $7.5(1.6)$ & $7.6(1.5)$ & $7.6(1.6)$ & 0.0128 \\
\hline Height $(\mathrm{cm})$ & $165.6(9.0)$ & $166.0(9.4)$ & $165.6(9.9)$ & 0.5839 & $165.7(9.4)$ & $166.0(9.1)$ & $166.5(9.1)$ & 0.0134 \\
\hline BMI $\left(\mathrm{kg} / \mathrm{m}^{2}\right)$ & $27.4(4.8)$ & $28.9(5.3)$ & $29.2(5.4)$ & $<0.0001$ & $28.2(5.2)$ & $28.4(5.1)$ & $29.5(5.4)$ & $<0.0001$ \\
\hline Total cholesterol (mmol/l) & $5.2(1.2)$ & $5.2(1.2)$ & $5.1(1.1)$ & 0.0248 & $5.2(1.2)$ & $5.1(1.2)$ & $5.3(1.2)$ & 0.4147 \\
\hline HDL-cholesterol (mmol/l) & $1.3(0.4)$ & $1.3(0.3)$ & $1.2(0.3)$ & 0.0001 & $1.3(0.4)$ & $1.2(0.4)$ & $1.2(0.4)$ & 0.2886 \\
\hline Systolic BP (mmHg) & $142.0(20.6)$ & $146.3(21.6)$ & $148.4(22.5)$ & $<0.0001$ & $145.2(21.6)$ & $142.8(20.6)$ & $144.4(21.9)$ & 0.0533 \\
\hline Diastolic BP (mmHg) & $80.4(10.6)$ & $81.0(11.2)$ & $80.2(11.1)$ & 0.9545 & $80.5(10.9)$ & $80.8(10.5)$ & $82.0(11.5)$ & 0.0004 \\
\hline Resting heart rate ${ }^{\mathrm{b}}$ & $74.6(11.8)$ & $74.1(12.1)$ & $73.2(12.5)$ & $<0.0001$ & $74.1(12.1)$ & $74.6(12.2)$ & $73.4(11.7)$ & 0.3251 \\
\hline Serum creatinine $(\mu \mathrm{mol} / \mathrm{l})$ & $84.4(25.5)$ & $87.5(26.1)$ & $89.1(23.7)$ & $<0.0001$ & $86.9(26.0)$ & $85.1(21.3)$ & $84.1(20.6)$ & 0.0012 \\
\hline Cognitive function (MMSE) ${ }^{\mathrm{c}}$ & $28.8(1.7)$ & $28.4(1.9)$ & $28.2(2.1)$ & $<0.0001$ & $28.5(1.9)$ & $28.6(1.8)$ & $28.6(1.7)$ & 0.0801 \\
\hline Quality of life (EQ-5D) & $0.8(0.2)$ & $0.8(0.2)$ & $0.8(0.2)$ & $<0.0001$ & $0.8(0.2)$ & $0.8(0.2)$ & $0.8(0.2)$ & $<0.0001$ \\
\hline Diabetes duration (years) & $7(3,11)$ & $7(3,12)$ & $6(3,11)$ & 0.3475 & $7(3,11)$ & $7(3,11)$ & $6(2,11)$ & 0.1008 \\
\hline Exercise $\geq 15 \mathrm{~min} /$ week $^{\mathrm{d}}$ & $0(0,7)$ & $0(0,6)$ & $0(0,6)$ & $<0.0001$ & $0(0,7)$ & $0(0,5)$ & $0(0,7)$ & 0.9679 \\
\hline Alcoholic drinks per week & $0(0,1)$ & $0(0,2)$ & $0(0,2)$ & $<0.0001$ & $0(0,2)$ & $0(0,3)$ & $0(0,3)$ & 0.0024 \\
\hline Female & $1,795(40.1)$ & $1,751(42.0)$ & $1,099(47.6)$ & 0.001 & $4,063(42.5)$ & $271(39.5)$ & $311(43.3)$ & 0.27 \\
\hline White/European ethnicity & $1,712(38.2)$ & 2,917 (69.9) & $1,920(83.2)$ & 0.001 & $5,677(59.4)$ & $399(58.2)$ & $473(65.8)$ & 0.001 \\
\hline Current cigarette smoker & $554(12.4)$ & $613(14.7)$ & $351(15.2)$ & 0.004 & $1,362(14.3)$ & $95(13.8)$ & $61(8.5)$ & 0.001 \\
\hline $\begin{array}{l}\text { Use of metformin or } \\
\text { beta-blocker }\end{array}$ & $3,120(69.7)$ & $2,973(71.2)$ & $1,645(71.3)$ & 0.22 & $6,766(70.8)$ & $482(70.3)$ & $490(68.2)$ & 0.24 \\
\hline $\begin{array}{l}\text { Needing assistance with } \\
\text { daily activities }\end{array}$ & $94(2.1)$ & $141(3.4)$ & $133(5.8)$ & 0.001 & $324(3.4)$ & $16(2.3)$ & $28(3.9)$ & 0.24 \\
\hline $\begin{array}{l}\text { History of major } \\
\text { macrovascular disease }\end{array}$ & $1,339(29.9)$ & $1,385(33.2)$ & $800(34.7)$ & 0.001 & $3,064(32.1)$ & $213(31.0)$ & $247(34.4)$ & 0.36 \\
\hline $\begin{array}{l}\text { History of major } \\
\text { microvascular disease }\end{array}$ & $426(9.5)$ & $448(10.7)$ & $271(11.7)$ & 0.013 & $998(10.4)$ & $80(11.7)$ & $67(9.3)$ & 0.36 \\
\hline $\begin{array}{l}\text { History of major diabetic } \\
\text { disease }\end{array}$ & $309(6.9)$ & $298(7.1)$ & $180(7.8)$ & 0.40 & $688(7.2)$ & $51(7.4)$ & $48(6.7)$ & 0.84 \\
\hline
\end{tabular}

Values are mean (SD) (for Age at baseline to Quality of life), median (interquartile range) (for Diabetes duration to Alcoholic drinks per week); all others $n(\%)$

${ }^{\mathrm{a}}$ Better oral health; ${ }^{\mathrm{b}}$ beats per min; ${ }^{\mathrm{c}}$ Mini Mental State Examination; ${ }^{\mathrm{d}}$ number of occasions 
slightly more likely to smoke cigarettes, report vascular disease and require assistance with activities of daily living. There was no apparent relationship between number of teeth and $\mathrm{HbA}_{1 \mathrm{c}}$ or diabetes duration. The association between number of days with bleeding gums and study characteristics was less clear. On the one hand, people reporting more bleeding days were somewhat younger, better educated, taller, had lower creatinine values and smoked less, relative to those reporting fewer days bleeding; however, they were also marginally heavier, and had higher diastolic and systolic BP. In general, the magnitude of associations between the two markers of oral disease and the various covariates was modest, with statistical significance often reached owing to the high study power.

In Table 2, HRs for the two indicators of oral health (number of teeth and bleeding gums) in relation to total mortality rates and various CVD outcomes during followup are depicted. In the most basic model (age-, sex- and treatment-adjusted), the group with no teeth experienced almost twice the risk of death from all causes (HR 1.78, 95\% CI 1.50-2.11) relative to those with 22 teeth or more. This effect was incremental across the teeth groups $(p<$ 0.0001 for trend), such that people with an intermediate number of teeth had intermediate risk (1.41, 1.20-1.65). Controlling separately for a series of covariates had very little impact on these effects estimates; however, adding all potential confounding factors simultaneously to the multivariable model did lead to some attenuation, although statistical significance at conventional levels $(p<$ $0.05)$ was retained. When fatal and non-fatal CHD (combined) events were the outcome of interest, the strength of the association with number of teeth in age-, sex- and treatment-adjusted analyses, while again inverse, was lower in magnitude than that evident for the analyses featuring all-cause mortality. Controlling for individual risk factors again had little impact on this gradient, but in the multiple adjusted analyses the association was eliminated. There was no apparent link between number of teeth and cerebrovascular disease (largely comprising stroke) in any of our analyses.

Men and women with fewer teeth experienced an elevated risk of death from CVD and non-CVD in age-, sex- and treatment-adjusted analyses. Although these gradients were weakened after control for potential confounding factors, particularly for CVD deaths, they remained robust to full adjustment, again with evidence of a dose-response effect. In none of our analyses did days of bleeding gums show any relationship with the five study outcomes.

In analyses using age rather than calendar time as the time scale, our Cox models revealed the same results as those described above. While there were too few events to stratify by each of the 215 study centres, we were able to do so by the five regions (Australasia and south-east Asia, Canada, China, Europe - continental, Europe - northern) in which each centre was located. There was no suggestion that this modified the impact of oral disease on any of the outcomes.

\section{Discussion}

The main finding of this study was that, following adjustment for a range of confounding variables, oral disease, as indexed by a lower number of teeth, was associated with total mortality and mortality ascribed to CVD and non-CVD, such that the highest risk was apparent in men and women reporting the fewest teeth. The association between a lower number of teeth and CHD was evident in most analyses, but was lost on multiple adjustment. Our other marker of oral disease (number of days with bleeding gums) was unrelated to any of these outcomes. This may be because few people reported any gum bleeding, thereby limiting statistical power; it also may be that, in comparison to tooth loss, gum bleeding does not capture oral disease severe enough to yield an effect on the study endpoints. Additionally, it is plausible that enquiring about bleeding gums over the preceding 12 months is asking too much of even the most attentive study member. A relationship between tooth loss and an increased risk of non-CVD death was also apparent in our analyses. Given that this outcome partially comprises malignancies, some of which have been linked with inflammatory markers [22], this association does not rule out systemic inflammation as the causal process linking oral disease with CVD.

Alternative (non-causal) explanations The two most likely alternative explanations for the observation that having fewer teeth is related to an excess disease risk are reverse causality and confounding. Although the prospective design of this cohort study largely rules out reverse causality, it is plausible that some participants entered the study with oral disease caused by existing CVD (and associated risk factors), either diagnosed or hidden, and that this generated a positive oral disease-CVD gradient. We examined this issue in two ways. First, we excluded study members with diagnosed CVD at study induction and repeated our analyses. Second, we dropped individuals who registered events in the first 2 years of follow-up and again repeated our analyses. The latter approach was based on the assumption that people entering the study with CVD or other important but occult co-morbidities would have been most likely to die from their condition in the early stages of follow-up. In both cases our results were essentially unchanged (results available upon request). 
Table 2 HR ( $95 \%$ CI) for the relation between baseline oral health and later health outcomes in ADVANCE ( $n=10,958$ men and women)

\begin{tabular}{|c|c|c|c|c|c|c|c|c|}
\hline \multirow[t]{2}{*}{ Adjustments } & \multicolumn{3}{|c|}{ Number of natural teeth } & \multirow{2}{*}{$\begin{array}{l}p \text { value } \\
\text { for trend }\end{array}$} & \multicolumn{3}{|c|}{ Days of bleeding gums/year } & \multirow{2}{*}{$\begin{array}{l}p \text { value } \\
\text { for trend }\end{array}$} \\
\hline & $\geq 22^{\mathrm{a}}$ & $1-21$ & 0 & & $0^{\mathrm{a}}$ & $<12$ & $\geq 12$ & \\
\hline$n$ & 4,476 & 4,174 & 2,308 & & 9,553 & 686 & 719 & \\
\hline \multicolumn{9}{|l|}{ Total mortality ( 1,011 deaths) } \\
\hline $\begin{array}{l}\text { Age, sex }+ \text { treatment } \\
\text { ('base' model) }\end{array}$ & 1 (ref) & $1.41(1.20-1.65)$ & $1.78(1.50-2.11)$ & 0.001 & 1 (ref) & $1.03(0.79-1.35)$ & $0.92(0.69-1.22)$ & 0.67 \\
\hline Base + ethnicity & 1 & $1.44(1.23-1.69)$ & $1.84(1.54-2.20)$ & 0.001 & 1 & $1.03(0.79-1.35)$ & $0.92(0.69-1.22)$ & 0.66 \\
\hline Base + quality of life & 1 & $1.36(1.16-1.59)$ & $1.70(1.44-2.02)$ & 0.001 & 1 & $1.02(0.78-1.34)$ & $0.87(0.66-1.16)$ & 0.45 \\
\hline Base + existing illness ${ }^{b}$ & 1 & $1.36(1.16-1.59)$ & $1.70(1.44-2.02)$ & 0.001 & 1 & $1.00(0.76-1.31)$ & $0.94(0.70-1.25)$ & 0.69 \\
\hline $\begin{array}{l}\text { Base }+ \text { behavioural CVD } \\
\text { risk factors }\end{array}$ & 1 & $1.38(1.18-1.62)$ & $1.73(1.46-2.05)$ & 0.001 & 1 & $1.05(0.80-1.37)$ & $0.95(0.71-1.26)$ & 0.86 \\
\hline $\begin{array}{l}\text { Base }+ \text { physiological } \\
\text { CVD risk factors }\end{array}$ & 1 & $1.36(1.16-1.59)$ & $1.71(1.44-2.03)$ & 0.001 & 1 & $1.05(0.80-1.38)$ & $0.93(0.70-1.24)$ & 0.77 \\
\hline $\begin{array}{c}\text { Base }+ \text { psychological } \\
\text { CVD risk factors }\end{array}$ & 1 & $1.33(1.14-1.56)$ & $1.66(1.40-1.97)$ & 0.001 & 1 & $1.03(0.79-1.35)$ & $0.88(0.66-1.17)$ & 0.47 \\
\hline $\begin{array}{c}\text { Base }+ \text { socioeconomic } \\
\text { CVD risk factors }{ }^{f}\end{array}$ & 1 & $1.40(1.20-1.63)$ & $1.76(1.48-2.08)$ & 0.001 & 1 & $1.06(0.81-1.38)$ & $0.95(0.71-1.26)$ & 0.86 \\
\hline Multiple adjusted ${ }^{\mathrm{g}}$ & 1 & $1.24(1.05-1.46)$ & $1.48(1.24-1.78)$ & 0.001 & 1 & $1.08(0.82-1.41)$ & $0.96(0.72-1.28)$ & 1.00 \\
\hline \multicolumn{9}{|l|}{ All CHD events ( 1,119 events) } \\
\hline $\begin{array}{l}\text { Age, sex }+ \text { treatment } \\
\text { ('base' model) }\end{array}$ & 1 (ref) & $1.27(1.11-1.46)$ & $1.38(1.17-1.62)$ & 0.001 & 1 (ref) & $1.21(0.96-1.52)$ & $1.07(0.84-1.36)$ & 0.26 \\
\hline Base + ethnicity & 1 & $1.17(1.01-1.35)$ & $1.22(1.03-1.45)$ & 0.02 & 1 & $1.21(0.96-1.52)$ & $1.04(0.81-1.32)$ & 0.38 \\
\hline Base + quality of life & 1 & $1.24(1.08-1.42)$ & $1.32(1.13-1.55)$ & 0.001 & 1 & $1.19(0.95-1.50)$ & $1.03(0.81-1.31)$ & 0.44 \\
\hline Base + existing illness ${ }^{b}$ & 1 & $1.21(1.05-1.39)$ & $1.26(1.07-1.49)$ & 0.003 & 1 & $1.22(0.97-1.54)$ & $1.08(0.85-1.38)$ & 0.22 \\
\hline $\begin{array}{c}\text { Base }+ \text { behavioural } \\
\text { CVD risk factors }\end{array}$ & 1 & $1.28(1.11-1.47)$ & $1.39(1.18-1.64)$ & 0.001 & 1 & $1.21(0.96-1.52)$ & $1.06(0.83-1.35)$ & 0.29 \\
\hline $\begin{array}{l}\text { Base }+ \text { physiological } \\
\text { CVD risk factors }\end{array}$ & 1 & $1.20(1.05-1.38)$ & $1.25(1.06-1.47)$ & 0.004 & 1 & $1.23(0.98-1.54)$ & $1.06(0.83-1.35)$ & 0.27 \\
\hline $\begin{array}{l}\text { Base }+ \text { psychological } \\
\text { CVD risk factors }\end{array}$ & 1 & $1.23(1.07-1.41)$ & $1.31(1.12-1.54)$ & 0.001 & 1 & $1.19(0.95-1.50)$ & $1.03(0.81-1.31)$ & 0.44 \\
\hline $\begin{array}{c}\text { Base }+ \text { socioeconomic } \\
\text { CVD risk factors }{ }^{f}\end{array}$ & 1 & $1.27(1.11-1.46)$ & $1.37(1.16-1.61)$ & 0.001 & 1 & $1.22(0.97-1.54)$ & $1.09(0.85-1.39)$ & 0.20 \\
\hline Multiple adjusted ${ }^{\mathrm{g}}$ & 1 & $1.24(0.98-1.56)$ & $1.04(0.81-1.32)$ & 0.34 & 1 & $1.24(0.98-1.56)$ & $1.04(0.81-1.32)$ & 0.34 \\
\hline \multicolumn{9}{|c|}{ All cerebrovascular disease events (668 events) } \\
\hline $\begin{array}{l}\text { Age, sex }+ \text { treatment } \\
\text { ('base' model) }\end{array}$ & 1 (ref) & $1.10(0.92-1.31)$ & $0.93(0.75-1.15)$ & 0.68 & 1 (ref) & $1.18(0.88-1.60)$ & $1.08(0.79-1.47)$ & 0.39 \\
\hline Base + ethnicity & 1 & $1.34(1.12-1.60)$ & $1.26(1.00-1.58)$ & 0.02 & 1 & $1.19(0.88-1.61)$ & $1.15(0.84-1.58)$ & 0.21 \\
\hline Base + quality of life & 1 & $1.07(0.90-1.28)$ & $0.90(0.73-1.12)$ & 0.47 & 1 & $1.17(0.87-1.59)$ & $1.05(0.77-1.43)$ & 0.51 \\
\hline Base + existing illness ${ }^{b}$ & 1 & $1.06(0.89-1.27)$ & $0.88(0.71-1.09)$ & 0.35 & 1 & $1.19(0.88-1.60)$ & $1.08(0.79-1.48)$ & 0.38 \\
\hline $\begin{array}{c}\text { Base }+ \text { behavioural } \\
\text { CVD risk factors }\end{array}$ & 1 & $1.09(0.92-1.30)$ & $0.93(0.75-1.15)$ & 0.66 & 1 & $1.19(0.88-1.61)$ & $1.08(0.79-1.48)$ & 0.38 \\
\hline $\begin{array}{l}\text { Base }+ \text { physiological } \\
\text { CVD risk factors }\end{array}$ & 1 & $1.12(0.94-1.33)$ & $0.95(0.77-1.19)$ & 0.87 & 1 & $1.22(0.90-1.64)$ & $1.13(0.82-1.54)$ & 0.25 \\
\hline $\begin{array}{c}\text { Base }+ \text { psychological } \\
\text { CVD risk factors }\end{array}$ & 1 & $1.06(0.89-1.26)$ & $0.89(0.72-1.10)$ & 0.39 & 1 & $1.18(0.87-1.59)$ & $1.05(0.77-1.43)$ & 0.51 \\
\hline $\begin{array}{c}\text { Base }+ \text { socioeconomic } \\
\text { CVD risk factors }{ }^{f}\end{array}$ & 1 & $1.10(0.92-1.31)$ & $0.93(0.75-1.15)$ & 0.68 & 1 & $1.20(0.89-1.62)$ & $1.11(0.81-1.52)$ & 0.20 \\
\hline Multiple adjusted ${ }^{\mathrm{g}}$ & 1 & $1.24(1.03-1.49)$ & $1.10(0.87-1.38)$ & 0.29 & 1 & $1.24(0.91-1.67)$ & $1.16(0.84-1.58)$ & 0.18 \\
\hline \multicolumn{9}{|l|}{ CVD mortality (536 deaths) } \\
\hline $\begin{array}{l}\text { Age, sex }+ \text { treatment } \\
\text { ('base' model) }\end{array}$ & 1 (ref) & $1.53(1.24-1.89)$ & $1.67(1.32-2.12)$ & 0.001 & 1 (ref) & $1.21(0.86-1.70)$ & $1.01(0.69-1.48)$ & 0.62 \\
\hline Base + ethnicity & 1 & $1.58(1.27-1.97)$ & $1.76(1.37-2.27)$ & 0.001 & 1 & $1.21(0.86-1.71)$ & $1.01(0.69-1.47)$ & 0.63 \\
\hline Base + quality of life & 1 & $1.46(1.18-1.80)$ & $1.58(1.25-2.00)$ & 0.001 & 1 & $1.20(0.85-1.69)$ & $0.95(0.65-1.39)$ & 0.87 \\
\hline Base + existing illness ${ }^{b}$ & 1 & $1.44(1.16-1.78)$ & $1.55(1.22-1.96)$ & 0.001 & 1 & $1.16(0.83-1.64)$ & $1.04(0.71-1.52)$ & 0.58 \\
\hline Base + behavioural & 1 & $1.51(1.22-1.87)$ & $1.66(1.30-2.10)$ & 0.001 & 1 & $1.22(0.87-1.73)$ & $1.02(0.70-1.49)$ & 0.57 \\
\hline
\end{tabular}


Table 2 (continued)

\begin{tabular}{|c|c|c|c|c|c|c|c|c|}
\hline \multirow[t]{2}{*}{ Adjustments } & \multicolumn{3}{|c|}{ Number of natural teeth } & \multirow{2}{*}{$\begin{array}{l}p \text { value } \\
\text { for trend }\end{array}$} & \multicolumn{3}{|c|}{ Days of bleeding gums/year } & \multirow{2}{*}{$\begin{array}{l}p \text { value } \\
\text { for trend }\end{array}$} \\
\hline & $\geq 22^{\mathrm{a}}$ & $1-21$ & 0 & & $0^{\mathrm{a}}$ & $<12$ & $\geq 12$ & \\
\hline $\begin{array}{l}\text { Base }+ \text { physiological } \\
\text { CVD risk factors }\end{array}$ & 1 & $1.47(1.19-1.82)$ & $1.60(1.26-2.04)$ & 0.001 & 1 & $1.24(0.88-1.76)$ & $1.02(0.70-1.49)$ & 0.55 \\
\hline $\begin{array}{l}\text { Base }+ \text { psychological } \\
\text { CVD risk factors }\end{array}$ & 1 & $1.43(1.16-1.77)$ & $1.54(1.21-1.95)$ & 0.001 & 1 & $1.21(0.86-1.71)$ & $0.95(0.65-1.39)$ & 0.85 \\
\hline $\begin{array}{l}\text { Base }+ \text { socioeconomic } \\
\text { CVD risk factors }{ }^{\mathrm{f}}\end{array}$ & 1 & $1.52(1.23-1.89)$ & $1.66(1.31-2.11)$ & 0.001 & 1 & $1.24(0.88-1.76)$ & $1.05(0.72-1.53)$ & 0.46 \\
\hline Multiple adjusted $^{\mathrm{g}}$ & 1 & $1.32(1.06-1.65)$ & $1.35(1.05-1.74)$ & 0.02 & 1 & $1.28(0.91-1.81)$ & $1.04(0.71-1.52)$ & 0.47 \\
\hline \multicolumn{9}{|c|}{ Non-CVD mortality (475 deaths) } \\
\hline $\begin{array}{l}\text { Age, sex + treatment } \\
\text { ('base' model) }\end{array}$ & 1 (ref) & $1.28(1.02-1.61)$ & $1.90(1.49-2.42)$ & 0.001 & 1 (ref) & $0.83(0.54-1.28)$ & $0.81(0.52-1.27)$ & 0.25 \\
\hline Base + ethnicity & 1 & $1.29(1.01-1.63)$ & $1.93(1.49-2.49)$ & 0.001 & 1 & $0.84(0.55-1.29)$ & $0.81(0.52-1.26)$ & 0.24 \\
\hline Base + quality of life & 1 & $1.24(0.99-1.57)$ & $1.84(1.45-2.35)$ & 0.001 & 1 & $0.83(0.54-1.27)$ & $0.79(0.51-1.22)$ & 0.19 \\
\hline Base + existing illness ${ }^{\mathrm{b}}$ & 1 & $1.27(1.01-1.60)$ & $1.88(1.48-2.40)$ & 0.001 & 1 & $0.81(0.53-1.25)$ & $0.82(0.53-1.27)$ & 0.24 \\
\hline $\begin{array}{l}\text { Base }+ \text { behavioural } \\
\text { CVD risk factors }\end{array}$ & 1 & $1.24(0.99-1.57)$ & $1.82(1.42-2.32)$ & 0.001 & 1 & $0.85(0.55-1.31)$ & $0.86(0.55-1.34)$ & 0.37 \\
\hline $\begin{array}{l}\text { Base }+ \text { physiological } \\
\text { CVD risk factors }{ }^{\mathrm{d}}\end{array}$ & 1 & $1.24(0.98-1.56)$ & $1.84(1.44-2.35)$ & 0.001 & 1 & $0.85(0.55-1.30)$ & $0.83(0.53-1.28)$ & 0.29 \\
\hline $\begin{array}{l}\text { Base }+ \text { psychological } \\
\text { CVD risk factors }\end{array}$ & 1 & $1.23(0.97-1.55)$ & $1.81(1.42-2.30)$ & 0.001 & 1 & $0.83(0.54-1.28)$ & $0.79(0.51-1.22)$ & 0.19 \\
\hline $\begin{array}{l}\text { Base }+ \text { socioeconomic } \\
\text { CVD risk factors }\end{array}$ & 1 & $1.26(1.00-1.59)$ & $1.86(1.46-2.37)$ & 0.001 & 1 & $0.85(0.55-1.31)$ & $0.83(0.53-1.29)$ & 0.29 \\
\hline Multiple adjusted ${ }^{\mathrm{g}}$ & 1 & $1.15(0.91-1.47)$ & $1.64(1.26-2.13)$ & 0.001 & 1 & $0.86(0.56-1.33)$ & $0.86(0.56-1.35)$ & 0.40 \\
\hline
\end{tabular}

Of the 1,119 CHD events, 327 were fatal and 792 non-fatal; of the 668 cerebrovascular events, 66 were fatal and 602 non-fatal

All analyses are adjusted for age, sex and randomised treatment allocation

${ }^{\text {a }}$ Better oral health

${ }^{\mathrm{b}}$ Comprises one or more of the following: use of metformin/beta-blockers, history of macrovascular or microvascular disease, need for assistance with daily activities, diabetes duration

${ }^{\mathrm{c}}$ Cigarette smoking, alcohol intake, vigorous physical activity in previous week

${ }^{\mathrm{d}} \mathrm{HbA}_{1 \mathrm{c}}$, creatinine, BMI, total cholesterol, HDL-cholesterol, resting heart rate, systolic BP, diastolic BP

${ }^{\mathrm{e}}$ Quality of life (EQ-5D score) and Mini Mental State Examination score

${ }^{\mathrm{f}}$ Age at completion of highest level of education, height

${ }^{g}$ All above covariates

ref, reference

The apparent detrimental effect of poor oral health on these outcomes was generally robust to the adjustment of a wide range of covariates (CVD risk factors, psychological well-being, socioeconomic adversity) that have been implicated in the causes of our disease endpoints, although some attenuation of risk was evident. Since marked attenuation following adjustment was apparent, and given that the association with CHD became non-significant with full statistical control, it is possible, as in all observational studies, that the gradients found by us could be explained by unmeasured covariates even in this well characterised study, or perhaps by more precise measurements of existing ones. In a related point, an alternative approach to examining the link between oral disease and mortality rates in type 2 diabetes would be to perform extended follow-up for CVD events in large-scale randomised controlled trials of treatments for oral disease where confounding would not be a concern.

The notion that our results may not be completely ascribed to the above alternative explanations at least signals the possibility that tooth loss may be mechanistically linked to CVD and non-CVD deaths. Reduced masticatory capacity impairs nutritional intake and this may in turn be a risk factor for CVD [23]. We did not collect data on dietary intake with which exploration of this possibility might have been possible. However, in, to our knowledge, the only study to capture information on food intake, adjusting for this behaviour did not eliminate the association between oral health and coronary artery disease [24]. As described, inflammation resulting from poor oral health has been implicated in the development of CVD [10], although, again, we did 
not have data on markers of systemic inflammation to test such a hypothesis.

Study strengths and limitations While this study has several strengths, including large sample size, high number of events and the sampling of a general population of type 2 diabetic patients, it also has some shortcomings. Measures of oral health were both self-reported, raising concerns regarding validity. While the enquiry about tooth loss is widely used in the field of dental epidemiology [9], the measure of gum bleeding is less common. However, having decided a priori to investigate the association of the latter with CVD and other health outcomes, we did not want to omit it from our manuscript simply because the results were null. This would lead to publication bias, a major problem in modern epidemiology [25].

In conclusion, in the present study of people with type 2 diabetes, oral disease, as indexed by fewer teeth, was related to an increased risk of death from all causes and of death due to CVD and non-CVD.

Acknowledgements The ADVANCE trial was funded by grants from Servier and the National Health and Medical Research Council of Australia. These sponsors had no role in the design of the study, data collection, data analysis, data interpretation and the writing of the manuscript. Study data were not made available to the sponsors. The management committee, whose membership did not include any sponsor representatives, had final responsibility for the decision to submit this manuscript for publication. The authors had full access to the study data and take responsibility for the accuracy of the analysis. The Medical Research Council (MRC) Social and Public Health Sciences Unit receives funding from the UK MRC and the Chief Scientist Office at the Scottish Government Health Directorates. D. Batty is a Wellcome Trust Career Development Fellow (WBS U.1300.00.006.00012.01). S. Czernichow holds a Fellowship awarded by the Institut Servier-France and Assistance Publique - Hôpitaux de Paris, France.

Duality of interest J. Chalmers holds research grants from Servier; J. Chalmers, B. Neal, A. Patel, S. Zoungas and M. Woodward have received lecturing fees from Servier. All other authors declare that there is no duality of interest associated with this manuscript.

\section{References}

1. Osler W (1908) Diseases of the arteries. In: Osler W (ed) Modern medicine: its theory and practice in original contributions by Americans and foreign authors, 4th edn. Lea and Fabiger, Philadelphia

2. Marcus SE, Drury TF, Brown LJ, Zion GR (1996) Tooth retention and tooth loss in the permanent dentition of adults: United States, 1988-1991. J Dent Res 75:684-695

3. Genco R, Offenbacher S, Beck J (2002) Periodontal disease and cardiovascular disease: epidemiology and possible mechanisms. J Am Dent Assoc 133(Suppl):14S-22S
4. Janket SJ, Baird AE, Chuang SK, Jones JA (2003) Meta-analysis of periodontal disease and risk of coronary heart disease and stroke. Oral Surg Oral Med Oral Pathol Oral Radiol Endod 95:559-569

5. Meurman JH, Sanz M, Janket SJ (2004) Oral health, atherosclerosis, and cardiovascular disease. Crit Rev Oral Biol Med $15: 403-413$

6. Mattila KJ, Pussinen PJ, Paju S (2005) Dental infections and cardiovascular diseases: a review. J Periodontol 76:2085-2088

7. Pihlstrom BL, Michalowicz BS, Johnson NW (2005) Periodontal diseases. Lancet 366:1809-1820

8. Geismar K, Stoltze K, Sigurd B, Gyntelberg F, Holmstrup P (2006) Periodontal disease and coronary heart disease. J Periodontol 77:1547-1554

9. Humphrey LL, Fu R, Buckley DI, Freeman M, Helfand M (2008) Periodontal disease and coronary heart disease incidence: a systematic review and meta-analysis. J Gen Intern Med 23: 2079-2086

10. Bahekar AA, Singh S, Saha S, Molnar J, Arora R (2007) The prevalence and incidence of coronary heart disease is significantly increased in periodontitis: a meta-analysis. Am Heart J 154: $830-837$

11. Dave S, van DT (2008) The link between periodontal disease and cardiovascular disease is probably inflammation. Oral Dis 14: 95-101

12. Petersen PE, Bourgeois D, Ogawa H, Estupinan-Day S, Ndiaye C (2005) The global burden of oral diseases and risks to oral health. Bull World Health Organ 83:661-669

13. Saremi A, Nelson RG, Tulloch-Reid M et al (2005) Periodontal disease and mortality in type 2 diabetes. Diab Care 28:27-32

14. The ADVANCE Collaborative group (2001) Study rationale and design of ADVANCE: Action in Diabetes and Vascular DiseasePreterax and Diamicron MR Controlled Evaluation. Diabetologia 44:1118-1120

15. Kengne AP, Czernichow S, Huxley R et al (2009) Blood pressure variables and cardiovascular risk. New findings from ADVANCE. Hypertension 54:399-404

16. Crum RM, Anthony JC, Bassett SS, Folstein MF (1993) Population-based norms for the Mini-Mental State Examination by age and educational level. JAMA 269:2386-2391

17. American Psychiatric Association (1994) Diagnostic and statistical manual of mental disorders. American Psychiatric Association, Washington

18. The EuroQol Group (1990) EuroQol - a new facility for the measurement of health-related quality of life. Health Policy 16:199-208

19. No authors listed (1992) International statistical classification of diseases and related health problems (10th revision). WHO, Geneva

20. Patel A, MacMahon S, Chalmers J et al (2008) Intensive blood glucose control and vascular outcomes in patients with type 2 diabetes. N Engl J Med 358:2560-2572

21. Cox DR (1972) Regression models and life-tables. J R Stat Soc (Ser B) 34:187-220

22. Balkwill F, Mantovani A (2010) Cancer and inflammation: implications for pharmacology and therapeutics. Clin Pharmacol Ther 87:401-406

23. Mann JI (2002) Diet and risk of coronary heart disease and type 2 diabetes. Lancet 360:783-789

24. Geerts S, Legrand V, Charpentier J et al (2004) Further evidence of the association between periodontal conditions and coronary artery disease. J Periodontol 75:1274-1280

25. Davey Smith G (2001) Reflections on the limitations to epidemiology. J Clin Epidemiol 54:325-331 